\title{
ASSESSING STUDENTS' PARTICIPATION UNDER DIFFERENT GROUP FORMATION STRATEGIES
}

\author{
Cristina Mesquita ${ }^{1,2}$, Rui Pedro Lopes ${ }^{1,3}$ \\ ${ }^{1}$ Instituto Politécnico de Bragança (PORTUGAL) \\ ${ }^{2}$ Research Center in Basic Education, Instituto Politécnico de Bragança (PORTUGAL) \\ ${ }^{3}$ Research Center in Digitalization and Industrial Robotics, Instituto Politécnico de Bragança \\ (PORTUGAL)
}

\begin{abstract}
The evolution of technology, the development of several economic sectors and the changes in the production and consumption of products has been changing the way people learn, how organizations work and, consequently, the value of specific, professional and social skills. The challenges people face in the development of their professions requires that they are able to solve complex problems, think critically, be creative, demonstrate emotional intelligence, be able to judge and make decisions, work with others and adapt to new situations.
\end{abstract}

Higher education institutions recognize that to promote the development of these aspects it is necessary to introduce changes in the way students learn and, consequently, in the way teachers teach. Literature highlights that traditional lectures are not able to actively involve students in the learning process. In this context, the use of small groups has been increasingly prevalent to foster students' interactivity and problem-solving skills. This presupposes that students are selected and integrated in specific teams, according to some group formation strategy.

Group formation can be performed by the students, allowing them to select their own teammates, or by the teacher, usually through a random or intentional selection. The intentional selection is guided by the students' skills to optimize the distribution of skills through the teams. In addition, teams can keep its formation through a significant amount of time, to develop a long-running task, or to develop several independent tasks during the semester, or can change, according to a jigsaw distribution of responsibilities or completely reset to new formations for each new task.

This study investigates how the dynamics in group formation, namely maintaining the team members unchanged through a significant amount of time or changing the group members frequently through the semester influences the development of each member's transversal skills as well as the success in the tasks. The group formation method follows both strategies, namely student-selected and random teacher-assigned in eight moments during the semester. The student participation and the outcome of each group is assessed through a qualitative research approach, based on two open questions questionnaire and one focus group. The questionnaires were developed in the beginning of the semester and in the end of the semester, immediately after the focus group. The focus group was developed in the end of the semester, with a representative set of 8 students in a total of four sessions with different students.

The experimental comparison was performed in the classes of Network and System Management $(\mathrm{N}=32)$ and Didactics of the Knowledge of the World $(\mathrm{N}=68)$. The qualitative data was obtained through students' written interview and the transcription of the focus group and categories inferred through content analysis.

The findings indicated that teacher-assigned groups outperformed student-selected groups in terms of outcome and also in the stimulation of individual student's participation. Overall, the results suggest that group formation method is a contributing factor to the success of group work.

Keywords: group formation, team of students, competences.

\section{INTRODUCTION}

The benefits of collaboration have been extensively described in the literature. Companies and other organizations recognize that adequate problem solving is more effective by teams of people, combining different experiences, values, and knowledge, than by individuals [1], [2]. Considered broadly as the "mutual engagement of participants in a coordinated effort to solve a problem together" 
[3], collaboration requires the work and participation of two or more individuals, following several models. Work can be divided among the participants and assumed independently for final integration when everyone finishes (usually designated cooperation [4]), or it can be shared by the participants, that can work both asynchronously, in which the participants are not required to work at the same time, or in face-to-face interactions [5]. In opposition to the first, collaboration refers to solving the problem through sharing skills, ideas and workload in close communication [6]. In other words, successful collaboration represents the construction of shared meanings for conversations, concepts, and experiences [7].

In educational context, collaborative learning characterizes a variety of educational approaches that appeals to joint intellectual effort between students or between students and teachers together [8]. Successful collaboration positively influences the students' achievement, persistence, and attitudes about learning, contributing to equal participation by all members of the group, working with the others in a collaborative and friendly way, increased conceptual learning or increased engagement, higher student achievement [9]-[11].

Research and practice have shown that this potential benefits are not always reached [12]. Despite the potential of collaboration, groups may also be prone to aggravation between individual members, leading to wasted time and feelings of discouragement. Individuals may also have their competence challenged, leading to a feeling of threat, reducing the exchange and integration of information and, consequently, to the success of the group [13].

However, because of the potential benefits, there has been an effort of integrating collaborative learning methodologies in the curricula of several programmes [2], [14], [15]. The continuing implementation of group work at schools and of teamwork in organizations are attempts to build on the potential of teamwork. Within the wide variety of collaborative learning activities, the learning process is based on the students' exploration or application of course contents. Everyone in the class is actively participating, working and discussing in small groups, driven by questions, problems or the challenge to create. Together, sharing ideas, discussing approaches, researching and implementing, students are developing their cognitive skills and, at the same time, approaching social skills towards successful team work.

Not all members share a common background and uniform knowledge. The overall result of the small groups work depends on the prior knowledge of the individuals as well as on the social relations developed within the group. In other words, the group formation influences both the task and knowledge development.

There are several strategies for group formation. Broadly, the groups can be formed by the students, by the teacher or independently, with the help of automated tools or applications. In the former, students tend to choose the colleagues with whom they feel comfortable or have previous personal relations. When the teacher announces that students should form teams for an assignment, they immediately start gesturing and giving indications to each other. Then, they take the initiative and announce that they want to work together. After students form teams they usually keep it for the remainder of the semester [16].

One problem with this method is that it can lead to less diverse teams and can leave students out, after the initial round of selection. These students, even after being integrated in some group, may have difficulties of integration in the self-selected group's social network, which can worsen the feeling of being left out and reduce the potential contribution of this element.

Another possibility is for the teacher to form teams, either by selecting random sets of students or by selecting students based on the perceived individual characteristics, according to some intentionality for the team operation. This requires that the teacher have some previous experience with the students and some knowledge about their social and cognitive traits. Random assignment means that each student in the class has an equal likelihood of being selected into a group. After decision of how many groups should exist in the class, the teacher assigns students to each group according to a random generation strategy (for example, using a deck of cards, a random number table, or others).

Random formation is easy to implement and seems to be fair [17]. However, the resulting groups may fail to combine a good set of skills or adequate diversity.

Finally, group formation can also be performed automatically, with the assistance of tools or applications. This is particularly useful for e-learning and online learning processes, in which students do not have frequent personal contact. Teams can be homogeneous or heterogeneous, formed according to the members' performance and personality traits [18]. The selection process is based on 
an optimization algorithm, that uses several variables to join students together. The optimization process can follow several algorithms and approaches, such as swarm optimization [19], [20], clustering algorithms [21], evolutionary algorithms [22], and others. For these to work, it is necessary to have prior information about the potential members as well as about team objectives and team members roles.

Regardless of the group formation strategy, there are tasks that are short duration and long duration. Teams can change to cope with different tasks or can endure until the end of the semester.

The main objective of the work described in this paper is to assess the students' perception regarding the impact of the different group formation strategies and the duration of the group in two dimensions: the success in solving the tasks and in the development of social skills. The later include the critical thinking and discursive skills in its members.

\section{METHODOLOGY}

Group formation, namely the strategy followed to gather students in a team, and group dynamics, maintaining the team unchanged or changing the members frequently through the semester, influences the development of each member's social skills as well as the success completing the tasks. The work described in this paper intends to study the perceptions of the students regarding these two dimensions, considering different group formation and dynamics strategies. The study was developed in the classroom, excluding online and e-learning scenarios. The experimental comparison was performed in the classes of Network and System Management $(\mathrm{N}=32)$ and Didactics of the Knowledge of the World ( $\mathrm{N}=68)$.

Group formation followed two strategies: student-selected and teacher-assigned (randomly). Since the groups were formed in class, automatic or application-assisted formation was not considered. Groups were formed in eight moments during the semester. The student participation and the outcome of each group was assessed through a qualitative research approach, based on three open-questions and one closed-question questionnaire and one focus group. The questionnaires were developed in the beginning of the semester and in the end of the semester, immediately after the focus group. The focus group was developed in the end of the semester, with a representative set of 8 students in a total of four sessions with different students.

The questionnaire was structured in five sections. The first section was used to characterize the respondents in terms of gender and course. Section 2 required the students to write an essay, with approximately 2000 characters, about their perceptions regarding the advantages and disadvantages of self-assigned teams of students. The next section asked the students to write an essay, also with 2000 characters, about their perceptions regarding the advantages and disadvantages of random assignment of students to teams. Section 4 asked the students to describe their opinion about the maintenance of the group composition or changing the group elements through the semester (1000 characters). Finally, the last section comprised 12 closed-questions asking the students to identify which of the options (student-selection vs. random assignment) they consider more adequate in relation to: exchange of experiences, respect by the diversity, distributed leadership, respect by the opinion of others, opportunities to know different ways of working together, individual and collective commitment, effectiveness of the solution, tendency for a single leader, development of discursive and discussion skills, task organization and distribution, equal opportunities, and preferred method.

The qualitative data was obtained through students' written answers and the transcription of the focus group and categories inferred through content analysis. The quantitative data was analysed through frequency analysis and descriptive statistics, discriminating the option most valued in each category.

In total, 47 answers were received and considered valid, with 22 from Didactics of the Knowledge of the World and 25 from Network and System Management (Figure 1). 


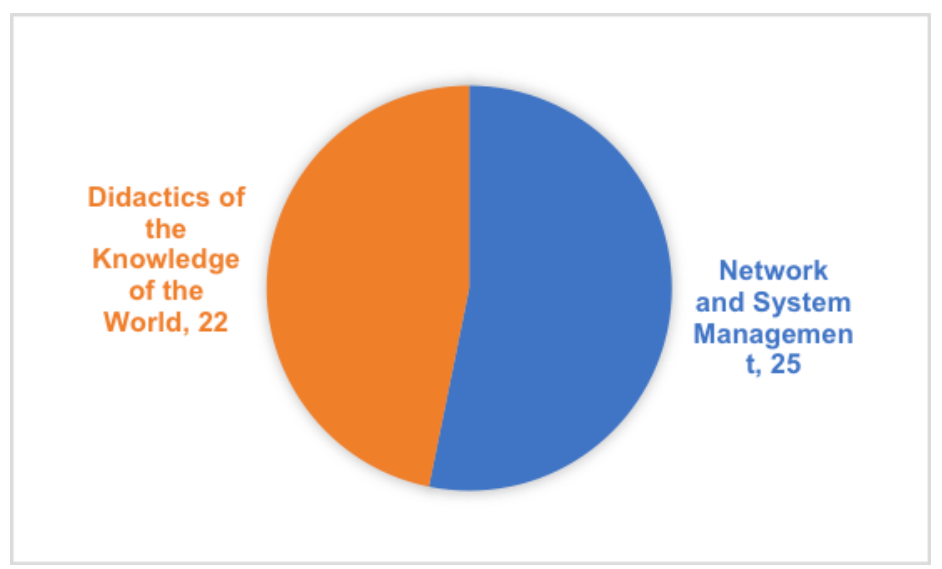

Figure 1. Number of respondents by course.

In relation to gender, as expected, the number of male students is higher in Network and System Management than in Didactics of the Knowledge of the World, with the number of female students higher in the second than in the first (Figure 2).

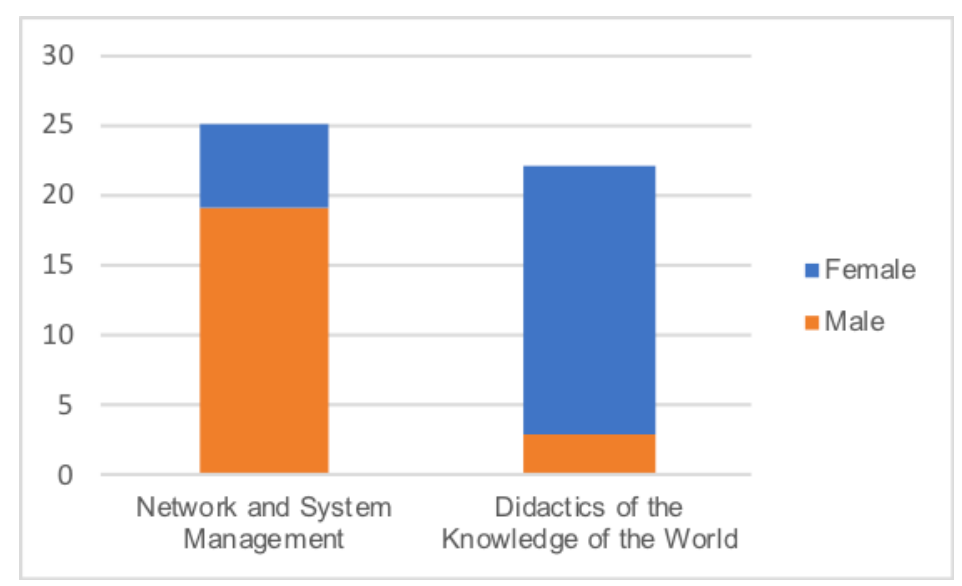

Figure 2. Number of respondents by course and by gender.

All the accepted responses fulfilled the required 2000 characters in the second section and the third section, and 1000 characters in the third section. The responses were imported into WebQDA for qualitative analysis through the identification of categories and sub-categories.

\section{RESULTS}

The initial step of the analysis was to build a system of categories, structured in themes, categories and sub-categories that were defined according to the objectives of the study. This study restricts the analysis to the social skills and the development of the task. Based on the collected data, the students' perceptions were interpreted based on heuristics analysis [23].

In total, students wrote 99663 characters (16500 words) describing the advantages and disadvantages of the student-selected group formation, 90539 (15005 words) describing the advantages and disadvantages of teacher-assigned group formation, and 65244 (10979 words) describing their perceptions about group maintenance or change throughout the semester.

The analysis was performed regardless of the question, considering all the text to infer the categories. In other words, the categories emerged from the analysis of the whole discourse of the students, grouped in five main themes: student-selected group formation, teacher-assigned groups, team work, change the groups with every new task, and maintain the groups formation throughout the semester. 


\subsection{Student-selected group formation}

Students are unanimous in referring that they prefer this method of group formation. They believe that if they feel comfortable, they are more available to learn:

Working in groups formed by students is always an advantage, because feeling comfortable is the best way to be "relaxed" in the learning process.

They clearly assume that they prefer choosing the colleagues with whom they feel comfortable with:

This method gives students' the responsibility to choose their team colleagues. In this case, it is normal, and it always happens, at least I speak for myself, we are able to work with the colleagues that we know better, are our friends, or that we had worked before, because it is easier because we already know what to expect.

Another advantage they identify is the previous knowledge of the team members. If they know their colleagues, they know what to expect, how to behave and this makes it easier to coordinate the work:

I prefer working with the colleagues I choose, because I know that I get along well with them, I know how they work and it is easier to coordinate the task development.

On the other hand, there are also some disadvantages. If the group elements stay together for a long time, some irritation or disagreements can occur, which can lead to poor working environment:

It will create a bad mood within the group and, in the next tasks, they will feel that the [disagreement] will happen again and the bad mood will continue.

They also identify, as disadvantage, that students may never be selected by their colleagues, either because they are not well known, they arrive late or they are shy:

The biggest disadvantage is to continue to isolate the members that were not able to form the groups in the beginning of the semester, by having got late or other reasons.

In these situations, changing the group elements may be beneficial.

\subsection{Teacher-assigned groups}

Although there are several possibilities for teacher-assigned groups formation, this theme refers only to randomly assigning students to teams. In the classroom, most of the random assignment was performed with a deck of cards, in which students selected cards randomly and they were put together according to the number of the card they drawn: ace, ones, twos, threes, and so on. This method works well for groups of four elements. With groups of more elements, the suite was used: clubs, spades, hearts and diamonds.

This random assignment appears to be fairer, since contributes to equal opportunities, in the sense that all the students have the same probability to belong to a given team:

When teachers select the groups, exclusion situations, confusion in the selection process and other problems do not happen.

In addition, they also think that this method of group formation contributes to further develop communication skills, since they have to come forward, overcome the shyness and assume the responsibility to allow the task to be successful:

Since the group members do not know each other well, they have to overcome the shyness and start communicating, which will help develop the communication skills of everyone with the people that they do not know or that they do not usually relate.

This attitude depends on the social skills of the members. If they cannot overcome the shyness, if they fail to start communicating, the work will suffer and the communication between the members may fail:

The main disadvantage is the fact of people not feeling comfortable with each other, reducing the communication.

Moreover, the random assignment of members can also lead to unbalanced teams, lacking equity or diversity:

There can be elements that are lazier in the development of the tasks, or with less individual responsibility, because some think that since the work is to be developed by several students, some will do the work for them. When working in teams, we are participating in a "team game", 
where we have to succeed. The product of our work will be presented orally or in written, by a representative of the group or by all its elements.

Regardless of the group formation strategy, students also have a rigorous perception of what it represents being a group member and the benefits of working together.

\subsection{Team work}

In relation to working in teams, it is possible to identify several categories in the students' text. In addition to the advantages and disadvantages, they also mention the competences developed, and the conditions for the successful development of the task.

Working in teams, regardless of the formation strategy, clearly contributes to equal opportunities, as described in the following excerpt:

There are more help and support between team mates. If one member has more difficulty with a task, all help, because all want to be successful. It is very stimulating both in the development of the task and in the learning process, always stimulating to do more and better, not for being better than the other members, but to increase the knowledge of all, so that all members win.

On the other hand, the disadvantages lie on the lack of commitment of some elements:

Impossibility to complete the task because some element forgot essential material that was of his responsibility.

Lack of responsibility and laziness:

Insufficient individual responsibility and tendency for laziness by some elements.

In addition to the cognitive knowledge developed with the development of the task, students identify the development of communication skills as the most relevant development resulting from team work:

It [working in teams] really helped me, mainly communicating with the others. I can say that I was a very shy person and I was always afraid of group work.

Of course, group work is only successful if a set of conditions are met. Members should demonstrate flexibility towards the exchange of ideas and integrating the others:

It can be successful, if there are some flexibility by some team members.

Work is also more successful if the team members have good communication and articulation:

If the group elements go along well, if they respect each other and the others' opinions, it is easy to work with them [...] the cooperation between the elements, help, shared responsibilities and balanced tasks contributes to successful and pleasant result.

Another condition for successful team work is the previous knowledge of the members abilities. Students constantly refer that if students know each other, the will work better together:

The fact of the students knowing each other and their work methods is very important, because it contributes to better cohesion and understanding throughout the development of the task.

Finally, responsibility is of paramount importance:

If the group has members that work but one promises to work but fails the objectives by lack of commitment or by laziness, this leads to the members working alone of by themselves.

Students realize that working in teams is important to their learning process and that prepares them better to work in the modern society. It helps them develop a set of competences that wouldn't exist otherwise. However, successful work depends on some conditions.

\subsection{Change the groups with every new task}

The students' perceptions regarding their participation in groups that change with every task is structured in advantages and disadvantages. The most remarkable advantage is the constant challenge they face when interacting with different colleagues in every task:

I have been having a notable development and facing new challenges because I have to learn to adapt and accept working with new people in several tasks. 
Different people are characterized by different knowledge, background, way of working and personality. This enriches the team work with a healthy diversity:

Each element has a different personality and his knowledge can be better in an area than in others. The elements complement each other, bringing new perspectives and approaches to each new task.

Equal opportunities are also identified as an advantage, since:

If each task were solved by different teams, students would have to work with everyone else, helping also the closest and the shyest.

They also refer learning different ways of working, better communication skills and better interpersonal relations:

Many times, we have to deal with a group that has to come quickly with creative solutions. I'm always learning new ways to come up with the best solution. Dealing with different people all the time contributes to widen our inter-personal relations.

Finally, maintaining the groups formation through the semester also has some advantages.

\subsection{Maintain the groups formation through the semester}

The main advantage is the deepening of personal relations:

In the groups that are kept unchanged through the semester I managed to create a deeper relation with the other members.

The disadvantages result from getting too much comfortable, which can lead to tense situations and difficulty in meeting the objectives and the deadlines:

Teams that don't change can result in less successful tasks. If the members are too much comfortable, the communication and coordination between them suffers, with members assuming all the work and others relaxing and failing to keep the shared responsibility.

They also identify less equality, since:

It continues to isolate the students that did not manage to form groups in the beginning of the semester, because they were late or any other reasons.

The qualitative analysis was complemented with quantitative analysis of the last part of the questionnaire. This last part asked the students to select which approach of group formation would be better in their opinion.

\subsection{Perception of the students}

The perception of the students in relation to several indicators regarding the two possibilities of group formation (groups formed by students and groups formed by the teacher) gives a clear understanding of how they like to work and their perceptions of the team work (Figure 3).

They understand that working with others helps them to learn different ways to work together and they feel that this is important for their development. They also value the exchange of experiences and the respect of the others' opinions.

Looking at the results from the better distribution of the tasks, more effectiveness, it is possible to understand that if they know each other's capacities and skills, work will be more successful. However, these indicators are unbalanced with the less commitment with the tasks and with the higher tendency for a single leader. Students recognize that in student-selected groups, although they are more productive, organized and successful, there is also less commitment and concentrated leadership, which is inconsistent.

The majority of students prefer the comfort of working with whom they know, maintain personal relations of have worked before instead of working with random colleagues. 


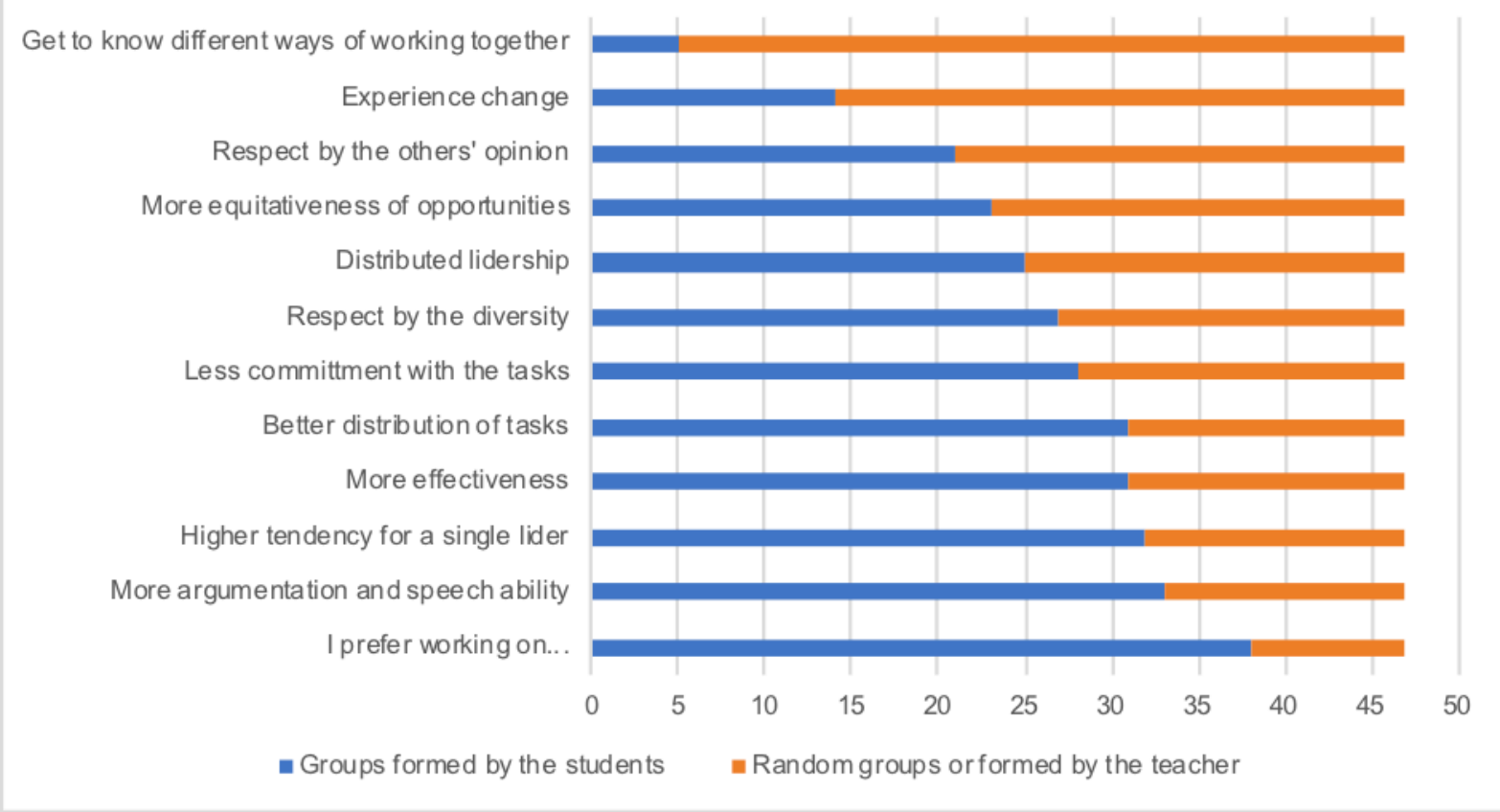

Figure 3. Frequency analysis of the group formation strategy.

The descriptive statistics of the students' perception is presented in Table 1.

Table 1. Descriptive statistics of the group selection strategy.

\begin{tabular}{|l|r|r|}
\hline & \multicolumn{1}{|c|}{ mean } & \multicolumn{1}{c|}{ sd } \\
\hline I prefer working on... & 1,80851064 & 0,39772712 \\
\hline More argumentation and speech ability & 1,70212766 & 0,46226727 \\
\hline Higher tendency for a single lider & 1,68085106 & 0,47118643 \\
\hline More effectiveness & 1,65957447 & 0,47897516 \\
\hline Better distribution of tasks & 1,65957447 & 0,47897516 \\
\hline Less committment with the tasks & 1,59574468 & 0,49605288 \\
\hline Respect by the diversity & 1,57446809 & 0,49976868 \\
\hline Distributed lidership & 1,53191489 & 0,50437494 \\
\hline More equitativeness of opportunities & 1,4893617 & 0,50529115 \\
\hline Respect by the others' opinion & 1,44680851 & 0,5025375 \\
\hline Experience change & 1,29787234 & 0,46226727 \\
\hline Get to know different ways of working together & 1,10638298 & 0,31166053 \\
\hline
\end{tabular}

\section{CONCLUSIONS}

Group and team work is valued by many companies and organizations, allowing to tackle more complex or longer tasks than individually. This study had the main objectives of assessing the students' perception regarding the impact of the different group formation strategies and the duration of the group in both the success in solving the tasks and in the development of social skills.

The data was collected through open and closed questions questionnaire and focus group, later analysed through qualitative and statistical analysis.

Students identify many advantages of team work, allowing them to learn different work methods, exchange of experiences and communication skills. In relation to student-selected vs. teacherassigned group formation, the majority prefer the first, mainly because they know the skills and abilities of the colleagues they are working with and because they feel comfortable with them. 
However, they recognize that teacher-assigned groups contribute to further develop their communication and socialization skills, although this opinion is not reflected or confirmed by their option in the last part of the questionnaire.

Finally, in relation to keeping the group unchanged throughout the semester or changing the group elements frequently, they prefer keeping a familiar work environment as long as the elements are responsible, committed, and available to discuss and work together.

From this study result that, although students prefer the student-selected group formation, they value more the competences and the characteristics that teacher-assigned group formation stimulates in them. Moreover, the challenges that arise from the organizations and from the modern society require that students are prepared to work with different people and to deal with the social diversity. In this sense, it is important, that team work allows them to contact with this cultural, social and intellectual diversity.

For this reason, education institutions should organize the courses and the methodologies in order to make effective and systematic the participation of students in groups that allows them to work with different colleagues.

\section{REFERENCES}

[1] P. Van den Bossche, W. H. Gijselaers, M. Segers, and P. A. Kirschner, 'Social and Cognitive Factors Driving Teamwork in Collaborative Learning Environments: Team Learning Beliefs and Behaviors', Small Group Res., vol. 37, no. 5, pp. 490-521, 2006.

[2] G. S. Stump, J. C. Hilpert, J. Husman, W. Chung, and W. Kim, 'Collaborative Learning in Engineering Students: Gender and Achievement', J. Eng. Educ., vol. 100, no. 3, pp. 475-497, 2011.

[3] J. Roschelle and S. D. Teasley, 'The Construction of Shared Knowledge in Collaborative Problem Solving', in Computer Supported Collaborative Learning, Springer, Berlin, Heidelberg, 1995, pp. 69-97.

[4] P. Dillenbourg, M. J. Baker, A. Blaye, and C. O'Malley, 'The evolution of research on collaborative learning', in Learning in Humans and Machine: Towards an interdisciplinary learning science., E. Spada and P. Reiman, Eds. Elsevier, Oxford, 1995, pp. 189-211.

[5] E. R. Lai, 'Collaboration: A literature review', Pearson, 2011.

[6] P. Dillenbourg, 'What do you mean by collaborative learning?', in Collaborative-learning: Cognitive and Computational Approaches, P. Dillenbourg, Ed. Oxford: Elsevier, 1999, pp. 1-19.

[7] A. S. Palincsar and L. R. Herrenkohl, 'Designing Collaborative Learning Contexts', Theory Pract., vol. 41, no. 1, pp. 26-32, Feb. 2002.

[8] B. L. Smith and J. MacGregor, 'What is collaborative learning?', in Collaborative Learning: $A$ Sourcebook for Higher Education, A. S. Goodsell and And Others, Eds. University Park, PA: National Center on Postsecondary Teaching, Learning, and Assessment, 1992.

[9] E. Michael Nussbaum, 'Collaborative discourse, argumentation, and learning: Preface and literature review', Contemp. Educ. Psychol., vol. 33, no. 3, pp. 345-359, 2008.

[10] K. C. Pollard, M. E. Miers, and M. Gilchrist, 'Collaborative learning for collaborative working? Initial findings from a longitudinal study of health and social care students', Health Soc. Care Community, vol. 12, no. 4, pp. 346-358, Jul. 2004.

[11] H.-J. So and T. A. Brush, 'Student perceptions of collaborative learning, social presence and satisfaction in a blended learning environment: Relationships and critical factors', Comput. Educ., vol. 51, no. 1, pp. 318-336, 2008.

[12] B. Barron, 'When Smart Groups Fail', J. Learn. Sci., vol. 12, no. 3, pp. 307-359, Jul. 2003.

[13] C. Buchs, D. Filippou, and C. Pulfrey, 'Reducing Threat in Cooperative Learning: The Role of Decentering', Int. Rev. Soc. Psychol., vol. 31, no. 1, Feb. 2018.

[14] J. Dijkstra, M. Latijnhouwers, A. Norbart, and R. A. Tio, 'Assessing the "l" in group work assessment: State of the art and recommendations for practice', Med. Teach., vol. 38, no. 7, pp. 675-682, 2016. 
[15] S. Bell, 'Project-Based Learning for the 21st Century: Skills for the Future', Clear. House J. Educ. Strateg. Issues Ideas, vol. 83, no. 2, pp. 39-43, 2010.

[16] L. Roy, 'Making speedy connections: how to encourage students to connect quickly for group work', Ref. Libr., vol. 59, no. 2, pp. 71-75, 2018.

[17] K. J. Chapman, M. Meuter, D. Toy, and L. Wright, 'Can't We Pick our Own Groups? The Influence of Group Selection Method on Group Dynamics and Outcomes', J. Manag. Educ., vol. 30, no. 4, pp. 557-569, 2006.

[18] N. Maqtary, A. Mohsen, and K. Bechkoum, 'Group Formation Techniques in ComputerSupported Collaborative Learning: A Systematic Literature Review', Technol. Knowl. Learn., 2017.

[19] S. Graf and R. Bekele, 'Forming Heterogeneous Groups for Intelligent Collaborative Learning Systems with Ant Colony Optimization', in Intelligent Tutoring Systems, 2006, pp. 217-226.

[20] M. R. D. Ullmann, D. J. Ferreira, C. G. Camilo, S. S. Caetano, and L. de Assis, 'Formation of learning groups in cMoocs using particle swarm optimization', 2015, pp. 3296-3304.

[21] C. E. Christodoulopoulos and K. A. Papanikolaou, 'A Group Formation Tool in an E-Learning Context', 2007, pp. 117-123.

[22] J. Moreno, D. A. Ovalle, and R. M. Vicari, 'A genetic algorithm approach for group formation in collaborative learning considering multiple student characteristics', Comput. Educ., vol. 58, no. 1, pp. 560-569, Jan. 2012.

[23] L. Bardin, Análise de Conteúdo. Edições 70, 2015. 